\title{
Santiago Nunes Ribeiro e José de Alencar: filhos presentes da literatura brasileira
}

Marcelo Peloggio I Funcap/CNPq/UFC

\begin{abstract}
Resumo: O artigo tem como objetivo traçar um paralelo entre os dois autores acerca da formação de nossa nacionalidade literária, no sentido de se pôr em destaque o pensamento de José de Alencar para a sua renovação e incremento.

Palavras-chave: José de Alencar, Santiago Nunes Ribeiro, nacionalidade literária.
\end{abstract}

O intercâmbio literário realizado por Brasil e Portugal, no correr do século 19, representa um campo de investigação demasiado vasto e profícuo, mas ainda pouco explorado para uma eventual sistematização. E isso não apenas no sentido de uma troca de experiências literárias entre o público leitor de ambos os países, que é o caso da circulação de obras; as ideias estéticas, o pensamento crítico, as formulações teóricas ultrapassam, de pleno direito, a mera notação bibliográfica. Por isso a necessidade de se dar continuidade aos estudos que têm por objeto as trocas culturais luso-brasileiras, tanto em termos de teoria como de prática, concernentes à literatura e sua história. 
Com efeito, o diálogo mantido entre as literaturas de Brasil e Portugal fora marcado por um vínculo muito mais estreito do que se poderia imaginar, e isso por iniciativa de ambos os lados, ainda que, no período compreendido, "a influência da literatura portuguesa no Brasil foi mais significativa que a da brasileira em Portugal".

E vínculo que se pode traduzir, as mais das vezes, por conta da ideia central da formação, no Brasil, de uma literatura patria, porque o diálogo firmado entre os dois lados do Atlântico compreenderá então um programa estético, sugerido pelos lusos, à nacionalidade mesma de nossas letras. Desde os primeiros anos após a independência política até fins do século 19, haverá um claro interesse português em dar curso à iniciativa literária de nossos escritores. Todavia, a resposta brasileira far-seá presente: é que as ideações estéticas lusitanas encontrarão ou a acolhida generosa, ou uma forte resistência, trazendo à luz a polêmica acerba e às vezes desmedida.

À ideia de formação da nossa literatura, a intelligentzia portuguesa mostrará ter uma opinião indivisa e uniforme: a que defende a exploração de um temário local (tropical) sob o modo de escrita lusitano, muitas vezes marcado por forte classicismo - o que explica à censura votada às inovações linguísticas dos escritores brasileiros, a serem aprofundadas, e de modo consciente, por José de Alencar.

Sob esse teor geral apresentam-se as posições de Almeida Garrett e Alexandre Herculano, continuadas mais tarde por Camilo Castelo Branco, Antero de Quental, Pinheiro Chagas, Sampaio Bruno, entre outros. Assim, parece ter constituído a "intromissão de além-mar" um dos pontos mais delicados nas relações culturais luso-brasileiras ao longo do século 19: incômoda a brasileiros (alguns tomados por um forte nativismo ou embalados pelo senso amplo da autonomia cultural) e cara a portugueses (dotados de um sentimento de tutela perdida, bem como o de uma natural liderança espiritual que reivindicavam para si).

No que diz respeito à linguagem, os críticos lusos vão encarar o jeito maleável de nossa escrita - fruto das "peregrinas blandícias da morbidez brasileira". - como forma de insubordinação gramatical. Garrett parece abrir a contenda, dizendo em seu "Bosquejo da história da poesia e língua portuguesa" (1826) que, apesar de ser "verdadeiramente nacional, e legítima americana", a poesia de O uraguay apresenta "incorreções de estilo"; por sua vez, Alexandre Herculano há de notar,

1. CRISTÓVÃO. Diálogos da casa e do sobrado: ensaios luso-brasileiros e outros p. 171.

2. CASTELO BRANCO. Curso de literatura portuguesa, p. 229.

3. GARRETT. Bosquejo da história da poesia e língua portuguesa, p. 34. 
em os Primeiros cantos, de Gonçalves Dias, algumas "imperfeições de língua, de metrificação, de estilo" ${ }^{4}$

Dando sequência a esse mesmo juízo, Antero de Quental observa que há, e em razão de problemas linguísticos, "pouco interesse pela literatura brasileira", de vez que "a língua brasileira já vai se diferenciando da portuguesa, não o suficiente para chegar a ser um dialeto, mas o suficiente para que pareça incorreta ao ouvido português".

Pinheiro Chagas, ao analisar Iracema, como que sintetiza o mal-estar que a experimentação linguística brasileira parece causar nos críticos portugueses:

O defeito que vejo em todos os livros brasileiros, e contra o qual não cessarei de bradar intrepidamente, é a falta de correção na linguagem portuguesa, ou antes a mania de tornar o brasileiro uma língua diferente do velho português, por meio de neologismos arrojados e injustificáveis, e de insubordinações gramaticais.

Ao fim do século 19, Sampaio Bruno expressará sentimento idêntico ao do autor de os Novos ensaios críticos ao dizer:

É um cúmulo; mas é assim mesmo. Entregam-se afincadamente a estudos gramaticais; manuseiam quotidianamente os clássicos quinhentistas; investigam as menores minúcias dos lexicólogos; e acabam por concluir que a língua brasileira é já suficientemente diferenciada do português para se constituir à parte e reger de casa própria.

E, com arrebatamento, Sena Freitas segue dilatando o ideal purista: "Arredem-me de diante dos olhos esse tupi moderno do nefelibatismo e do peregrinismo, para o qual muitas vezes nem resta o recurso do dicionário." ${ }^{8} \mathrm{Ou}$ ainda:

4. Herculano. Futuro literário de Portugal e do Brasil [1847], p. 98.

5. Cf. SAYERS. Onze estudos de literatura brasileira, p. 204.

6. CHagas. Novos ensaios críticos, p. 221.

7. BRUNO. O Brasil mental. Esboço crítico p. 82-83 (grifo do autor).

8. FREITAS. Lutas da pena, p. 185. 
Vem cá, língua do meu berço, língua de meus pais, de meus maiores, dos varões ilustres da minha nação, das epopéias da minha glória nacional, das crônicas da minha história, da idade áurea da minha literária pátria.

Essa defesa aguerrida do padrão linguístico de orientação lusa, ou mais simplesmente o português não falado à brasileira, mas de acordo com o sistema de regras e expressão fixado pela ex-metrópole, traduz a ideia de considerar nossa produção literária como fruto de um mesmo e único cânone - o da literatura portuguesa. No entender de Garrett, por exemplo, brasileiros e lusos, por falarem a mesma língua, devem pois fazer parte de um só sistema literário, no caso, o de Portugal. Diz ele: "E agora começa a literatura portuguesa a avultar, a enriquecerse com as produções dos engenhos brasileiros."

Opinião que desbarata os esforços de luta pela fundação da literatura pátria no Brasil.

Escrevendo em 1842 para o Jornal do Commercio, em reposta ao brasileiro Abreu e Lima, que defendera teses antilusitanas, Gama e Castro negaria a existência da literatura brasileira por não the reconhecer a autonomia, até porque "a literatura não toma o nome da terra, toma o nome da língua".

Garrett, a seu turno, traz a opinião de que o passo dos escritores brasileiros leva a marca do tutelado; assim, "Camões fixou a língua, a poesia e a literatura de todos os povos que descenderam da grande família lusitana. É preciso granjear, no nosso terreno, [diz Garrett] a parte da herança que nos tocou ao fazer partilhas".

Dentro do programa estético lusitano à nacionalidade mesma de nossas letras, revindica-se maior atenção à cor local brasileira, de modo a incrementar uma temática de índole tropical. A descrição, o tratamento estético dos elementos da terra - isto é, seus primeiros habitantes, a fauna, a flora, as águas, enfim, seu exotismo - serão pontos focados pela crítica lusa na obra dos escritores brasileiros, os quais, além de escreverem "incorretamente" o português, não levavam em conta, também, as belezas naturais de seu país e sequer os costumes de sua gente.

Garrett, no "Bosquejo da história da poesia e língua portuguesa", já acusava em nossos árcades o pouco engenho americano no tratamento de seus

9. FREITAS. Lutas da pena, p. 183.

10. GARRETT. Bosquejo da história da poesia e língua portuguesa, p. 32-33.

11. Citado por RIBEIRO. O saí e a serpente: diálogos entre José de Alencar e Pinheiro Chagas, p. 377-389. 
temas e imagens; indica a educação europeia como responsável por amesquinharlhes "o espírito nacional", que deve vicejar em meio às "majestosas e novas cenas da Natureza". ${ }^{12}$ Por isso defende a ideia de uma musa, que não encontra entre os nossos autores, torneada pela "sombra das palmeiras", pelo "sabiá terno e melodioso", pelas flores de "lustroso cafezeiro".

O mesmo ponto de vista nos é trazido por Herculano, isto é, o autor de Eurico, opresbitero lamenta, igualmente, a pouca nacionalidade dos escritores brasileiros:

Nos poetas transatlânticos há por via de regra demasiadas reminiscências da Europa. Esse Novo Mundo que deu tanta poesia a Saint-Pierre e a Chateaubriand é assaz rico para inspirar e nutrir os poetas que cresceram à sombra das suas selvas primitivas. ${ }^{14}$

Portanto, é o sentimento de natureza que deve estar ao centro, a ser embalado a toda força pela imaginação americana, compondo assim um matiz, de que também nota a ausência nos poetas brasileiros Camilo Castelo Branco, ${ }^{15}$ e o qual seria fundamental para a expressão do maravilhoso nos trópicos. Censura a ser renovada por Teófilo Braga, já que a poesia lírica dos árcades brasileiros, composta "no meio da natureza luxuriante do Brasil, vem buscar às desbotadas paisagens da Europa as cores mal desenhadas das Academias". ${ }^{16}$

Essa censura, com efeito, atingirá também o romantismo, como mostra os dizeres de Pinheiro Chagas sobre Gonçalves Dias: "As suas predileções são as de um poeta do nosso hemisfério"; ${ }^{17}$ ou ainda: "Gonçalves Dias pinta como o touriste, que, vendo um sítio pitoresco, traça à pressa o seu esboço nas páginas do álbum de viagem." ${ }^{18}$ Assim, pois, deve-se encarar o Brasil, escreve um dos seus filhos em Portugal, como "país encantador, de que nunca se disse tanto que não

12. GARRETT. Bosquejo da história da poesia e língua portuguesa, p. 33.

13. GARRETT. Bosquejo da história da poesia e língua portuguesa, p. 34.

14. HERCUlanO. Futuro literário de Portugal e do Brasil [1847], p. 98.

15. CASTELO BRANCO. Curso de literatura portuguesa [1876], p. 227.

16. BRAGA. Manual da história da literatura portuguesa. Desde as suas origens até ao presente p. 442.

17. CHAGas. Ensaios críticos, p. 168.

18. CHAGas. Ensaios críticos, p. 171. 
ficasse merecendo muito mais, sobre o qual a natureza, com pródiga mão, derramou a cornucópia de suas graças". ${ }^{19}$

À luz das opiniões de Garrett e Herculano, os críticos portugueses fazem disseminar a noção de que nossa nacionalidade literária é inexistente. E isso pelos seguintes motivos já indicados: a celebração da natureza, as gestas e os sentimentos dos povos indígenas, a descrição do meio ambiente, tudo isso parece não inspirar ou entusiasmar nossos poetas; e ainda que retirem daí a matéria e o assunto de seus cantos, vão se exprimir à brasileira, de modo que fora do padrão linguístico de Portugal não há literatura possível no Brasil.

Entre os autores de nosso período romântico, o culto à natureza constitui assunto primeiro, ao lado da valorização do elemento aborígine, seus usos e costumes. Gonçalves de Magalhães, por exemplo, sob inspiração francesa, enfatizará, com alguma afetação e exagero, aspectos de nossa flora e fauna. ${ }^{20}$

É em face, então, de toda a teoria e crítica sobre o cunho pátrio de nossas letras que aponta com singular destaque a figura do chileno Santiago Nunes Ribeiro. Radicado em solo brasileiro desde a infância, toma amor pela terra que o acolhe, fazendo-o reverberar numa atitude sensata, pois que trata de nossa formação espiritual não pelo lado estreito e acachapado do nativismo, mas numa dimensão americana, isto é, mais ampla e profunda. Ou como observa Afrânio Coutinho, o autor parece se antecipar à ideia de um "sentimento íntimo", elaborada mais tarde por Machado de Assis:

No exame das poesias brasileiras [diz Santiago Nunes Ribeiro] cumpre não ver somente a exterioridade da arte, que muitas vezes apresenta as formas gregas e romanas; cumpre atender ao sentido oculto, à intimidade, ou pelo menos ao elemento da poesia tradicional que nela se acha combinado ao elemento americano. ${ }^{21}$

Daí que "a poesia do Brasil é filha da inspiração Americana". ${ }^{22}$ Senso de universalidade que o alia à concepção defendida por Alencar da poesia como expressão da "divindade" e ao mesmo tempo da "humanidade do homem", como

19. FREITAS. Estudos críticos sobre a literatura do Brasil, p. 12.

20. MAGALHÃES. Ensaio sobre a história da literatura do Brasil, p. 154.

21. Citado por COUTINHO. Caminhos do pensamento crítico, p. 30.

22. NUNES RIBEIRO. Da nacionalidade da literatura brasileira, p. 47. 
mostrada na crítica acerba do autor de Iracema ao poema épico de Gonçalves de Magalhães - A confederação dos tamoios.

Sentimos que ambos os autores partem do um pressuposto fundamental: o que não toma a obra de arte como um fim em si mesmo, ou o conceito ingênuo da "arte pela arte", no qual o produto artístico estaria encerrado numa esfera privilegiada desligada do mundo exterior, bem como servindo ao gosto estético de um público específico. Ainda que amantes do belo, sob inspiração clássica, Alencar e Santiago Nunes Ribeiro não fogem à vertente romântica que enxerga no produto da arte uma realização, poder-se-ia dizer, "pedagógica". Com efeito, essa pedagogia pode ser traduzida como "missão", já que para o autor chileno "neutralizar, pois, os efeitos da instrução danosa que esses livros [as obras materialistas] nos hão dado, elevar depois o sentimento moral à altura da sua divina essência, é sem dúvida a missão da literatura atual dos grande povos. ${ }^{23}$

Em suas "Cartas sobre A confederação dos tamoios" (1856), Alencar é tomado, igualmente, pela mesma concepção: a de que o poeta, o artista em geral, como divulgador do belo, tem a cumprir "uma alta missão social". ${ }^{24}$ Como portador de uma verdade estética, ao fazer surgir um mundo novo, dizendo o passado, ou saudando o futuro, confirma quão poderoso é o uso da sua linguagem.

Então já não é o poeta que fala [diz Alencar]; é uma época inteira que exprime pela sua VOZ as tradições, os fatos e os costumes; é a história, mas a história viva, animada, brilhante como o drama, grande e majestosa como tudo que nos aparece através do dúplice véu do tempo e da morte. ${ }^{25}$

Em seu artigo "Da nacionalidade da literatura brasileira" (1843), como resposta ao luso Gama e Castro, que dizia não haver literatura no Brasil, Santiago Nunes Ribeiro mostra ter uma clara perspectiva histórica do fenômeno literário, fugindo ao crivo das noções definitivas e absolutas.

Conforme mostrado, o contendor luso toma por base o idioma para julgar da nacionalidade ou não das manifestações literárias de um país; refuta, portanto, nossa autonomia espiritual, já que escrevendo no idioma de Camões, os autores brasileiros não fazem outra coisa senão dilatar a abrangência da literatura

23. NUNES RIBEIRO. Da nacionalidade da literatura brasileira, p. 31.

24. ALENCAR. Cartas sobre A confederação dos tamoios, p. 890.

25. ALENCAR. Cartas sobre A confederação dos tamoios, p. 891. 
portuguesa. Curiosamente, como foi visto, exigem os portugueses dos escritores brasileiros mais atenção à cor local, a fim de se nacionalizar as letras da ex-colônia.

Em relação à censura feita aos árcades brasileiros, que desprezariam, segundo os críticos portugueses, os temas locais, reage Santiago Nunes Ribeiro com elevado senso de historicidade - sobretudo à acusação de não haver índole nacional na poesia de Tomaz Antônio Gonzaga. Diz o chileno:

O poeta fez cousa melhor: deu a essas liras consagradas ao seu ídolo o abandono, o mimo, a graça indefinível da paixão satisfeita e venturosa. (...) a disposição dos espíritos [à época dos árcades] não permitia que a natureza fosse encarada sob o aspecto que hoje nos agrada tanto, e que não é lícito exigir de um século aquilo que ele não pode dar. ${ }^{26}$

E arremata: "a sociedade os não entenderia". ${ }^{27}$ Essa percepção demasiado profunda do modo muito próprio do sentir e pensar das diferentes gerações, em diferentes etapas do desenvolvimento histórico, coloca o pensamento de Santiago Nunes Ribeiro muito adiante do seu tempo, quando contrastado com os apelos nativistas de um Gonçalves de Magalhães, ou de um Abreu e Lima, a quem Gama e Castro respondeu aos ataques infundados contra a inteligência portuguesa.

Alencar, em O nosso cancioneiro (1874), a exemplo de escritos anteriores, ${ }^{28}$ adota noção similar: a de que, tal qual a sociedade, isto é, como manifestação desta, a linguagem é dinâmica, não refletindo senão a "mentalidade" de um período e suas necessidades primeiras de expressão verbal. Assim, desde o início da ocupação, diz o autor de O guarani,

os povoadores do Brasil, e após eles seus descendentes, estão criando por todo este vasto império um vocabulário novo, à proporção das necessidades de sua vida americana, tão outra da vida européia.

Nós, os escritores nacionais, se quisermos ser entendidos de nosso povo, havemos de falar-lhe em sua língua, com os termos ou locuções que ele entende, e que lhes traduz os usos e sentimentos. ${ }^{29}$

26. NUNES RIBEIRO. Da nacionalidade da literatura brasileira, p. 39.

27. NUNES RIBEIRO. Da nacionalidade da literatura brasileira, p. 41.

28. Ver ALENCAR. Pós-escrito [1870], p. 243.

29. ALENCAR. O nosso cancioneiro, p. 23. 
Em outras palavras, a individualidade de um povo constitui o resultado de seu mecanismo social e histórico, ou antes, a expressão do interagir da coletividade com o indivíduo, a desdobrar-se em fatos linguísticos, morais, culturais, entre outros, que se particularizam, a cada época, num quê demasiado próprio. Essa visão de mundo, com efeito, nada tem de idealista; não suplanta a vida em nome de uma "lógica intrínseca" dos conceitos; pelo contrário, leva em consideração, em seu último grau, a dinâmica mesma do desenvolvimento histórico, marcada pelo embate de "ideias" objetivamente consideradas. Por isso o questionamento de Santiago Nunes Ribeiro, ao medir a realidade brasileira a partir da intromissão e arrogância lusas:

Agora perguntemos se um país, cuja posição geográfica e constituição geognóstica, cujas instituições, costumes e hábitos tanto diferem da sua metrópole de outrora, não deve ter sua índole especial, seu modo próprio de sentir e conceber, dimanante destas diversas causas, modificadas umas pelas outras; se, numa palavra, não deve ter caráter nacional. Sim, nos dirá todo aquele que estiver desprevenido. A literatura é a expressão da indole, do caráter, da inteligência social de um povo ou de uma época. ${ }^{30}$

Partindo da mesma opinião - da literatura como símbolo das usanças e costumes de um povo -, Alencar vê na contribuição estrangeira "um veículo de novas idéias e um elemento da civilização nacional”. ${ }^{31}$ Refuta, por conseguinte, tal como o faz o escritor chileno, o idealismo português: quimera de se reconquistar o Brasil mediante a imposição linguística e espiritual. Visão romântica dos lusos, sem dúvida, que se elide na argumentação lúcida e mesmo materialista do criador de Iracema. É que os conceitos chamados "rígidos" desvanecem-se, perdendo força e extensão em face da complexidade da própria vida. Mudança a valer, de igual modo, para o fenômeno linguístico, que é a resultante do interagir humano, social e historicamente situado, e não propriamente dos conceitos, que surgiriam depois. Logo, "os operários da transformação de nossas línguas são esses representantes de tantas raças, desde a saxônica até a africana, que fazem neste solo exuberante amálgama do sangue, das tradições e das línguas". ${ }^{32}$

30. NUNES RIBEIRO. Da nacionalidade da literatura brasileira, p. 36.

31. ALENCAR. Pós-escrito, p. 244.

32. ALENCAR. Pós-escrito, p. 244. 
Santiago Nunes Ribeiro e José de Alencar não professam, desse modo, uma visão mecânica da vida. O primeiro, por sua geração, poderia estar afeito ao determinismo lógico de Hegel, o segundo, ao das doutrinas materialistas do final do século 19, que então buscavam entrever a chave do mundo nas leis da biologia ou do meio ambiente. São ambos os autores, em verdade, a expressão de uma vontade tenaz, isto é, em mostrar, da maneira a mais razoável possível, que os ditames da arte traduzem as sugestões e influências das condições históricas em que estes dominaram ou feneceram. Mas muito mais que isso, na amplitude de seu pensamento americano, procuraram ser incisivos, argumentando que a literatura de uma sociedade em formação, como era o caso no Brasil, como era o caso em toda a América, não nasceria da ação das ideias, e sim, complexamente, das ideias da ação.

Abstract: The article has as its purpose making a parallel between the two authors when it comes to the formation of our literary national identity, specially calling attention to José de Alencar's thoughts for its renewal and enlargement. Keywords: José de Alencar, Santiago Nunes Ribeiro, National Literary Identity.

$$
\text { Referências }
$$

ALENCAR, José de. Cartas sobre A confederação dos tamoios. In: Obra completa. Rio de Janeiro: José Aguilar, 1960. v. IV, p. 863-922.

ALENCAR, José de. O nosso cancioneiro (cartas ao Sr. Joaquim Serra). ESTEVES, Manuel; CAVALCANTI PROENÇA, M. (Introdução e Notas). Rio de Janeiro: Livraria São José, 1962.

ALENCAR, José de [1870]. Pós-escrito. In: ___ Iracema. Lenda do Ceará. São Paulo: MEC/Instituto Nacional do Livro, Edição do Centenário, 1965. p. 183-205.

BRAGA, Teófilo. Manual da história da literatura portuguesa. Desde as suas origens até ao presente. Porto: Livraria Universal de Magalhães \& Moniz, 1875.

BRUNO, Sampaio. O Brasil mental. Esboço crítico. Porto: Livraria Chardron, 1898.

CASTELO BRANCO, Camilo. Curso de literatura portuguesa [1876]. 2. ed. Lisboa: Editorial Labirinto, 1986.

CHaGas, Pinheiro. Ensaios críticos. Porto: Viúva Moré-Editora, 1866.

CHAGAS, Pinheiro. Novos ensaios críticos. Porto: Viúva Moré-Editora, 1868. 
COUTINHO, Afrânio (Org.). Caminhos do pensamento crítico. Rio de Janeiro: Ed. Americana/Prolivro, 1974. v. I.

CRISTÓVÃO, Fernando. Diálogos da casa e do sobrado. Ensaios luso-brasileiros e outros. Lisboa: Edições Cosmos, 1994

FREITAS, José Antônio de. Estudos críticos sobre a literatura do Brasil. Lisboa: Tipografia das Horas Românticas, 1877.

FREITAS, Sena. Lutas da pena. Lisboa: Tipografia Universal, 1901.

GARRETT, Almeida. Bosquejo da história da poesia e língua portuguesa. In: Obras completas. Lisboa: Círculo de Leitores, 1984. p. 7-50.

HERCUlANO, Alexandre. Futuro literário de Portugal e do Brasil [1847]. In: DIAS, Gonçalves. Poesia completa e prosa. Rio de Janeiro: José Aguilar, 1959. p. 96-98.

MAGALHÃES, Gonçalves de. Ensaio sobre a história da literatura do Brasil. Niterói. Revista brasiliense, Paris, Dauvin et Fontaine, t. I, n. 1, p. 132-59, 1836.

NUNES RIBEIRO, Santiago. Da nacionalidade da literatura brasileira. In: COUTINHO, Afrânio (Org.). Caminhos do pensamento crítico. Rio de Janeiro: Ed. Americana/ Prolivro, 1974. p. 30-61. v. I.

RIBEIRO, Maria Aparecida. O saí e a serpente: diálogos entre José de Alencar e Pinheiro Chagas. In: Sentido que a vida faz. Porto: Campo das Letras, 1997. p. 377-89.

SAYERS, Raymond. Onze estudos de literatura brasileira. Trad. Roberto Raposo. Rio de Janeiro: Civilização Brasileira; Brasília: INL, 1983. 